\title{
Bevacizumab-IRDye 800CW
}

National Cancer Institute

\section{Source}

National Cancer Institute. Bevacizumab-IRDye 800CW. NCI Thesaurus. Code C101261.

An immunoconjug ate and a fluorescent tracer consisting of the recombinant humanized anti-vascular endothelial growth factor (VEGF) monoclonal antibody bevacizumab conjug ated to the N-hydroxysuccinamide (NHS) ester form of the near-infrared (NIR) fluorescent dye IRDye 800CW, that may be used for VEGF-specific tumor imaging. Upon administration, the bevacizumab moiety of bevacizumab-IRDye 800CW binds to VEGF and the fluorescent signal can be visualized using NIR fluorescence imaging (700-1,000 $\mathrm{nm})$. 